\title{
Paper
}

\section{Designating Locations with Specific Requirements in the English Midlands using ArcGIS}

\author{
Dale Steele* ${ }^{*}$ Member, Rong Zhang ${ }^{\dagger}$ Member
}

(Received June 17, 2013, revised July 12, 2013)

\begin{abstract}
This paper describes a method of using a GIS (Geographic Information System) software system to resolve a specific issue. The objective is to find an appropriate location for a new aggregate quarry. Another main goal is to locate the quarry in an area where it will have the least effect on unexcavated or existing archaeological features. To perform this task a number of stipulations have been established. These stipulations will act as guidelines during the search for the new quarry site location. This paper uses a step by step approach for the assimilation of these guidelines into the GIS-based search for this new location. Although this study focuses on archaeological applications of GIS, using this or a similar methodology would enable users to resolve spatial issues in a wide variety of different fields.
\end{abstract}

Keywords: GIS, aggregate extraction, desk-based assessment, shapefile, buffer zone, raster, polygon, alluvium

\section{Introduction}

A Geographic Information System (GIS) is not one, giant, monolithic software application. But rather, in the words of Wheatley and Gillings, it should be viewed more as a "spatial toolbox" (p.9) [1]. It is considered a powerful device to collect, store, retrieve, transform and display spatial data from the real world for special purposes in different research fields [1]. Conolly and Lake explain that a GIS describes the world in terms of attributes and locations. These two descriptors allow a GIS to present us with an accurate depiction of the real world. The attributes record what is actually present and, of course, the locations record where it is [2]. GISs allow individuals to capture, store, analyze and manage spatial data. These systems are used in a wide variety of fields. Some examples are Transportation Engineering [3] [4], Police Investigations [5], Hydrology studies [6], Water and Waste Management [7], Map Making [8], Wildlife Studies [9], Environmental Management [10] and Forestry [11] [12].

This study is intended to provide an example of the uses of a Geographic Information System (GIS). Although the focus of this study is essentially for archaeological purposes the systematic use of GIS can be applied in this manner to many different fields. The actual purpose of the study is to establish a site for a new gravel and sand, or aggregate, quarry in the Dove River Valley in central England. Several specific criteria have been established for guiding the selection process. Using these criteria three potential sites

\footnotetext{
* University of East Asia

2-1 Ichinomiyagakuencho, Shimonoseki city, Yamaguchi, Japan (dasteele2@gmail.com)

$\dagger$ Nishinippon Institute of Technology

1-2-11 Muromachi, Kokurakitaku, Kitakyushu city, Fukuoka, Japan
}

were researched and selected. From these three potential sites only one will be selected at a later date for the actual site.

Aggregate extraction is an important economic activity in this area and the Trent Valley is one of the principal sand and gravel producing regions in the United Kingdom. According to Yorke roughly three million tons are quarried every year with some areas generating up to 100,000 tons per hectare [13].

Sponsored by English Heritage, significant research has been done in the last fifteen years to understand the geoarchaeological history of the Trent Valley. As White points out, monitoring of quarry sites in the Trent Valley has brought to light numerous examples of archaeological remains, such as fish traps, revetments, anchor stones, bridges and mill dams [14]. Most of this material, though, is of a post-glacial nature. When palaeolithic material was found it was usually unanticipated [14].

More attention should perhaps be focused on understanding the northern extent of palaeolithic occupation and land use. Earlier research done in areas of aggregate extraction concentrated on areas of more recent geological deposits. White suspects that this is why most of the archaeological material discovered was of a post-glacial nature [14]

Palaeolithic features are usually associated with caves and only rarely discovered in open air sites. Reviews of previous research, though, have shown that "a number of the quarry complexes within the area have yielded Palaeolithic artefacts..." (p.18) [13]. This indicates potential for Palaeolithic finds. Ice during the last glaciation did not cover the entirety of the Trent Valley. It only blocked the Humber Estuary and entered into the Uttoxeter area. This allowed meltwater to deposit sands and gravels across the valley floor. About 13,000 years ago the river entered the 
deposits and created a terrace. This area saw increased hunter-gatherer activity. The Palaeolithic site at Farndon near Newark is an example of this statement [14].

The River Trent is the farthest river north in the UK where Palaeolithic artefacts have been located. Most research into Palaeolithic Britain has taken place in southeast England. As one moves from the southeast toward the northern boundary of known Palaeolithic activity the knowledge of that time period becomes distinctly less due to a lack of detailed research.

Some questions come to mind. Was this area the northern frontier of homo sapiens or earlier human penetration of the UK? What stresses were the populations operating under? Flint was difficult to find. Were other non-flint artefacts being missed or under reported?

In order to expand on the existing knowledge base for this time period it seemed reasonable to coordinate research efforts with those of practitioners of aggregate extraction. As mentioned before the Trent Valley is one of the principal sand and gravel producing regions in the United Kingdom. In 2001 Trent Valley Geoarchaeology was established. It was realized that with the Trent Valley being a major producer of sands and gravels, current extraction levels would likely continue or increase. It seemed reasonable to coordinate extraction with the continually expanding knowledge base about the river terraces and floodplains in the region. "The organization is a cooperative of stakeholders including researchers, heritage managers and industrial representatives. It provides a mutually supportive framework for multidisciplinary research within the region which is of benefit to the entire community" (p.20) [15].

It benefits all to cooperate even though there are divergences of needs and opinions. The perception of risk differs between members of the aggregate extraction community and Archaeology and Heritage professionals. Archaeologists worry about "incomplete understanding of the significance of remains, or the unexpected discovery of material for which no mitigation provision exists" (p.9) [16]. Members of the aggregate extraction community often view archaeological remains as a potential obstacle creating time and economic delays.

Because of these conflicting concerns it is becoming necessary to establish a method to characterize and distribute information regarding the possibility of encountering archaeological remains within existing aggregate deposits. By doing this one can mitigate both the risk of delay and expense when encountering remains for the aggregate community and the risk of incomplete research for the Archaeological community.

The purpose of this paper is to provide a desk-based assessment of a portion of the River Trent Valley. The intent is to locate three potential sites within the Dove River Valley which could accommodate aggregate extraction without having a detrimental effect on the environment or on natural, cultural or scientific sites. Further assessment will most likely be required before a final decision can be made.

\section{Aims and Objectives}

The principal objective of this study is to review the entire Dove River Valley in order to propose three potential sites from within the river terrace deposits where it may be acceptable to undertake aggregate extraction. Only one site is scheduled to be selected for quarry licensing and development. The aggregate extraction is intended to focus on either sand and gravel or alluvium. The planned extent of the new quarry will be established at 100 hectares or one square kilometer.

In order to ensure that areas of natural, historical or scientific significance are not disrupted, several specific restrictions and planning conditions have been stipulated. The quarry site must avoid all:

\section{Sites of Special Scientific Interest (SSSI)}

\section{Areas of Outstanding Natural Beauty (AONB)}

\section{Sites of Surviving Ancient Woodland}

4. All Scheduled Ancient Monuments (SAM) including their settings. This means the quarry site cannot encroach within 100 meters of a SAM.

It will need to have access to appropriate infrastructure. In order to accomplish this, the site needs to be, at minimum, partially accessible to a road of class B or above within a distance of 250 meters. Because of the risk of flooding the site will not be permitted within 100 meters of an existing waterway. Throughout the river valley there are many areas of urban or other development. In order to disturb residents as little as possible the new site cannot be within 200 meters of a built up area. The quarry site should also have as insignificant an affect as possible on other known sites of cultural heritage.

When undertaking this type of research an efficient method of presenting results is to offer visual examples in addition to written explanations. For this research maps proved to be an illustrative means to present data. Using maps provides accurate information regarding the location of the three sites being considered. Maps also allow the sites to be situated in areas where they can avoid the stipulated exclusionary factors.

Data for this research was assembled from a number of different datasets. A dataset provided by the Institute of Archaeology and Antiquity at the University of Birmingham was instrumental in assembling maps of the region. Geological information was downloaded from the Edina Digimap website. Further data was located at the Natural EnglandPublications and Maps website. This data was assembled to create the maps used to illustrate the solutions arrived at to resolve this project. The software used was ArcGIS version 10 from ESRI.

After opening ArcGIS geographical data from the University of Birmingham dataset was added. Rivers data was added. Rivers data is a polyline representation of the Trent River Valley. The Dove River Valley is a small portion of the Trent River Valley. To easily recognize it a polygon 


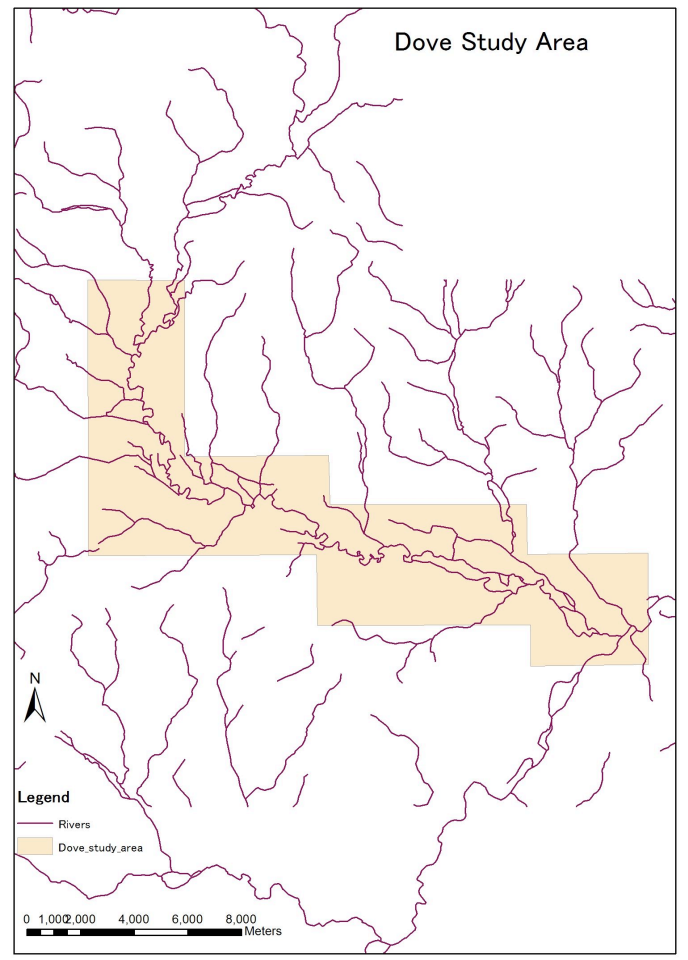

Figure 1: Rivers polyline.

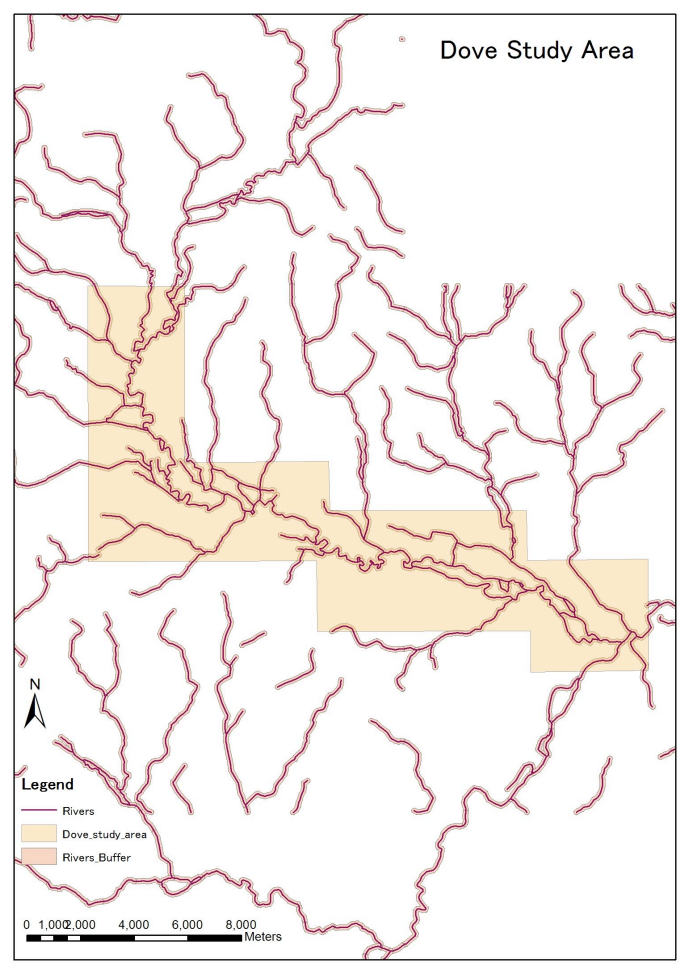

Figure 2: Buffer zone on each side of all the rivers.

shapefile was placed over the region of the Dove Valley. To ensure a clear view the map was zoomed to the extent of the Dove River Valley. A bookmark was created within ArcGIS

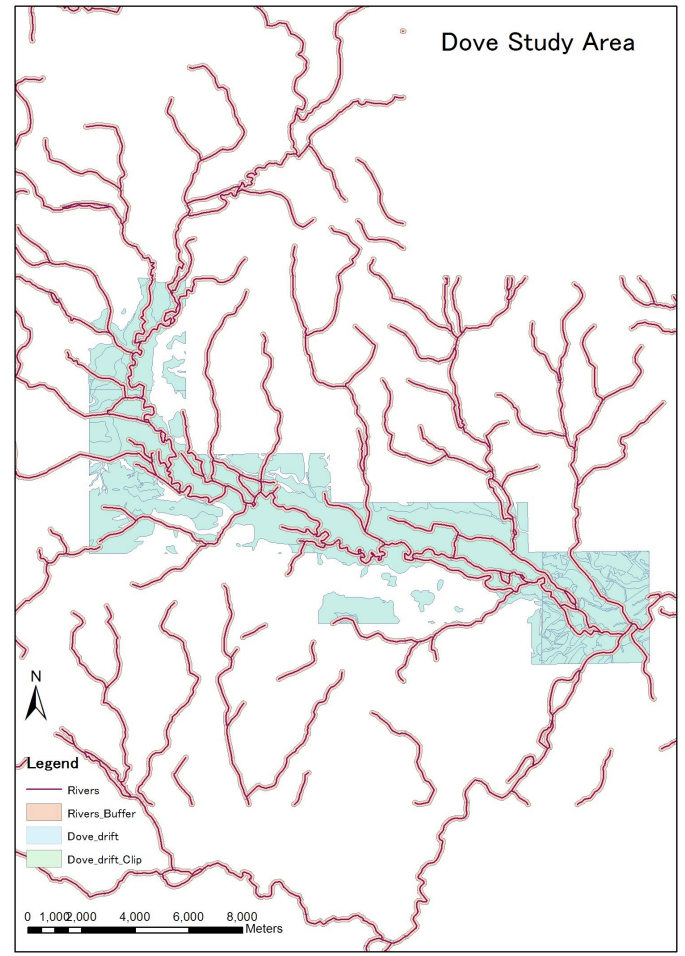

Figure 3: Aggregate areas.

to allow rapid access to this specific region. The polygon shapefile was opaque making the Rivers polyline not viewable. The polygon shapefile properties were opened and the transparency of the shapefile was adjusted to $60 \%$, thus allowing the Rivers polyline to be viewed (Fig. 1).

One requirement was that the quarry site must not be located within 100 meters of an existing watercourse. An effective method of doing this is to create a buffer zone around the rivers. A polygon shapefile was created with a buffer zone of 100 meters on each side of all the rivers. Using buffer zones allows one to locate the sites without encroaching upon the limitations around the watercourses (Fig. 2).

In order to recognize aggregate geology, data needed to be introduced. Dove drift and Dove drift clip data files were added from the University of Birmingham. Drift refers to sand and gravel deposits. These are polygon shapefiles representing the geology of the Dove River Valley. These polygons also were opaque requiring a transparency adjustment. By querrying the polygons using the Identify tool it became possible to discover the geology that each polygon represented allowing aggregate areas to be identified (Fig. 3).

Locating roads and built up areas was also required. Three raster files representing standard road maps in the Trent Valley were introduced. These were placed under the polyline and partially transparent polygon layers, thus allowing all layers to become visible (Fig. 4).

Raster based road maps are useful in establishing routes and boundaries but at times they proved to be somewhat ambiguous. Non-specific geometric shapes appeared on the maps, leaving it unclear as to what they represented. It was 


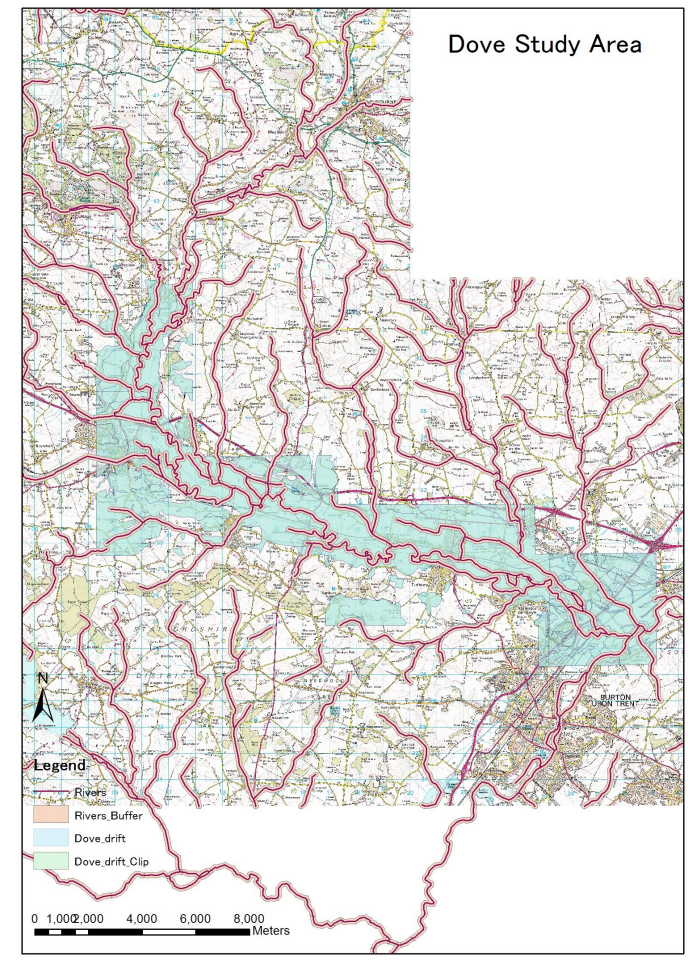

Figure 4: Trent Valley.

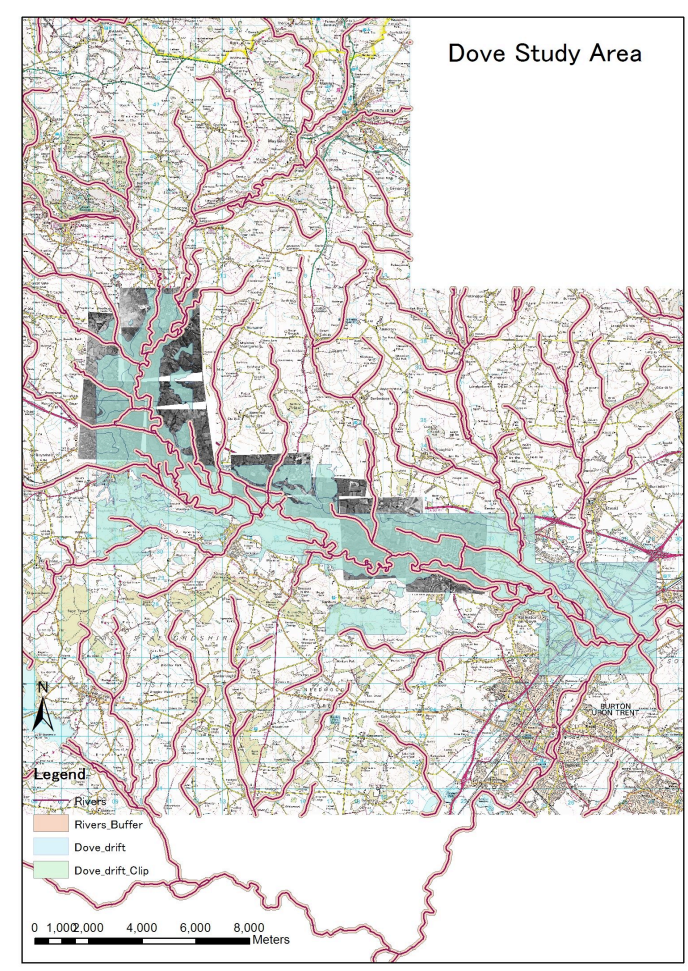

Figure 5: Aerial photographs introduced GIS.

unknown whether built up areas or large areas of tress and vegetation were being indicated. To accurately visualize what is on the ground aerial photography is useful. Aerial

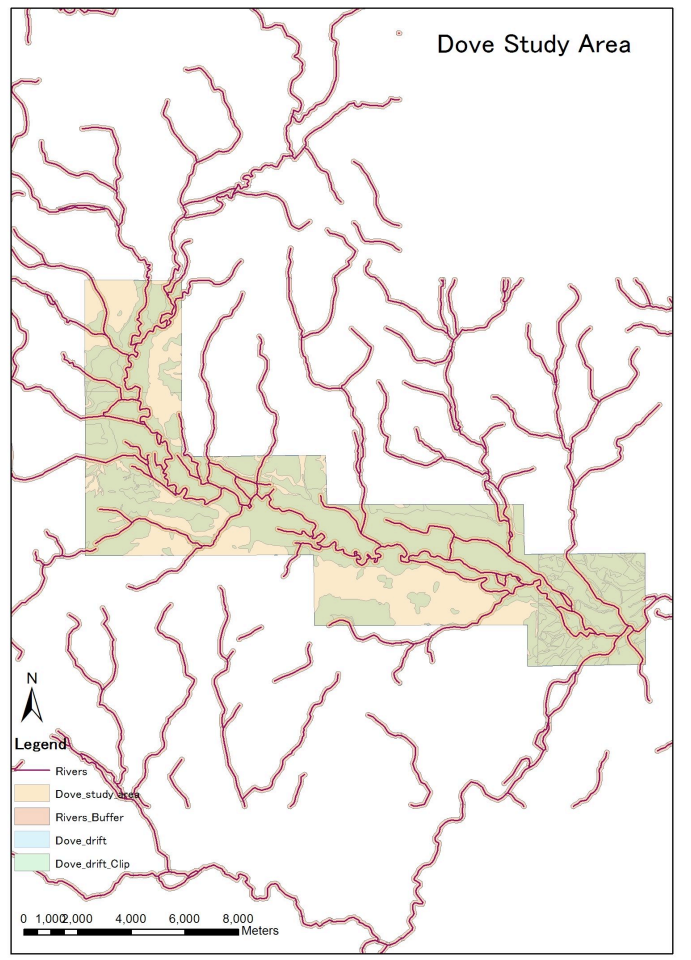

Figure 6: Geology data loaded GIS.

photographs were introduced into the GIS. This proved to be useful in identifying what lay on the ground in areas under consideration for the final site (Fig. 5).

It was imperative to identify the underlying geology in order to locate areas of acceptable aggregate. As mentioned above, geology data was loaded into the GIS. This proved to be very useful in identifying areas of aggregate, up to a point. The geology data was set only to the extent of the Dove River Study Area polygon (Fig. 6).

In several instances areas of aggregate appeared to extend beyond the borders of the polygon. If the extent of the aggregate was sufficient these areas appeared to have potential. But there was no way of visualizing exactly how far these areas of aggregate actually extended. The Edina Digimap website was searched and a clearer perspective of previously undetermined areas was visualized. Although, ultimately, the three selections were made from within the Dove River Study Area this additional knowledge assisted in that determination.

All Sites of Special Scientific Interest (SSSI) needed to be avoided. The Natural England-Publications and Maps website was searched. A shapefile indicating all the existing SSSIs was downloaded. This was placed upon the England polygon. The Rivers shapefile was added. The Dove River Study Area semi-transparent polygon was entered. The map was zoomed to the extent of the Dove River Valley and bookmarked. All SSSIs located near the Dove Valley were now visible (Fig. 7).

Shapefiles of all Areas of Outstanding Natural Beauty (AONB), sites of surviving Ancient Woodland and Sched- 


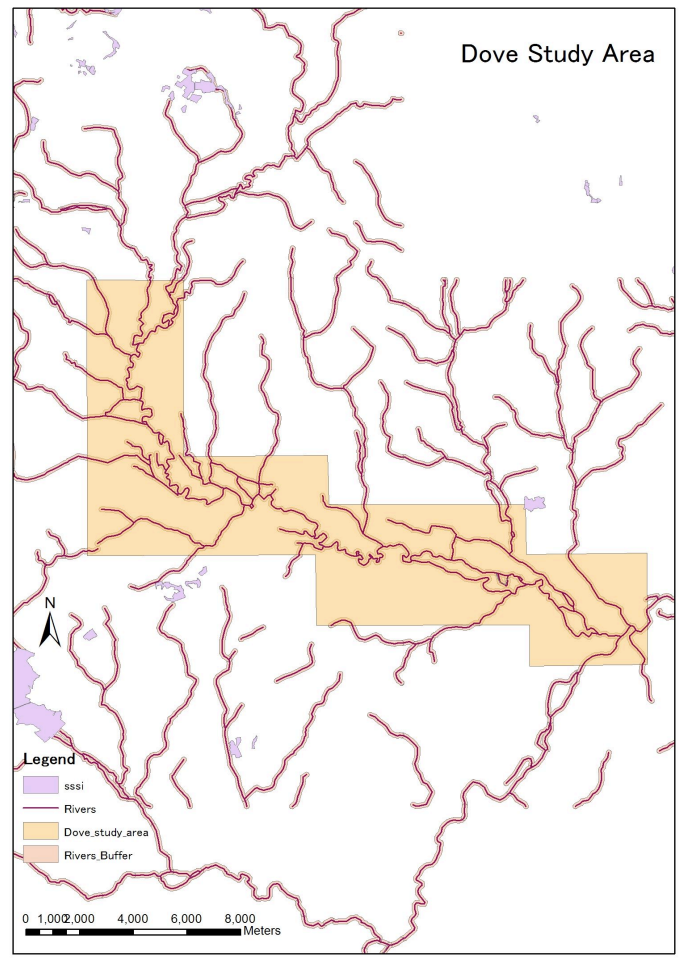

Figure 7: SSSIs location near the Dove Valley.

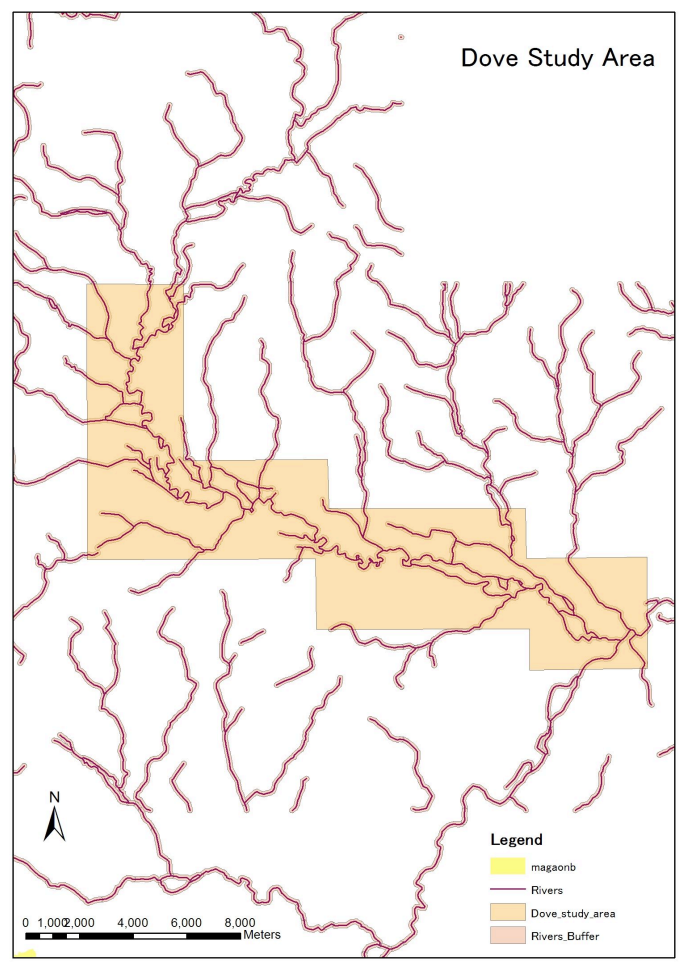

Figure 8: Areas of Outstanding Natural Beauty (AONB).

uled Ancient Monuments (SAM) were downloaded from the same website. The same procedure used to create the SSSI map was followed for each of these datasets and

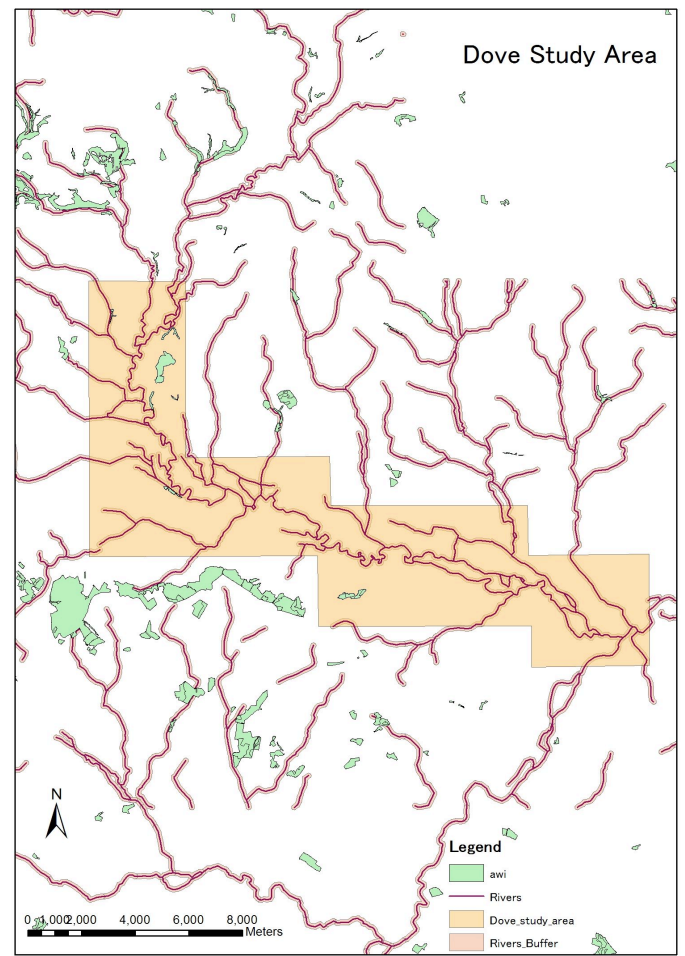

Figure 9: Surviving Ancient Woodland.

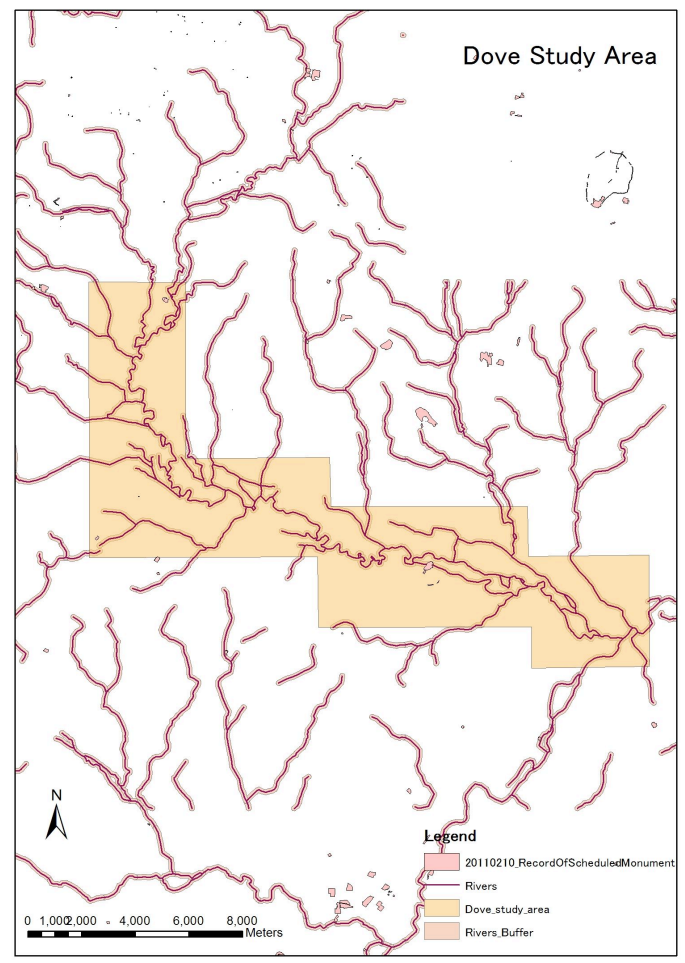

Figure 10: Scheduled Ancient Monuments (SAM).

individual maps were produced for each feature category (Fig. 8, Fig. 9 and Fig. 10).

A new polygon shapefile was created to contain the poly- 


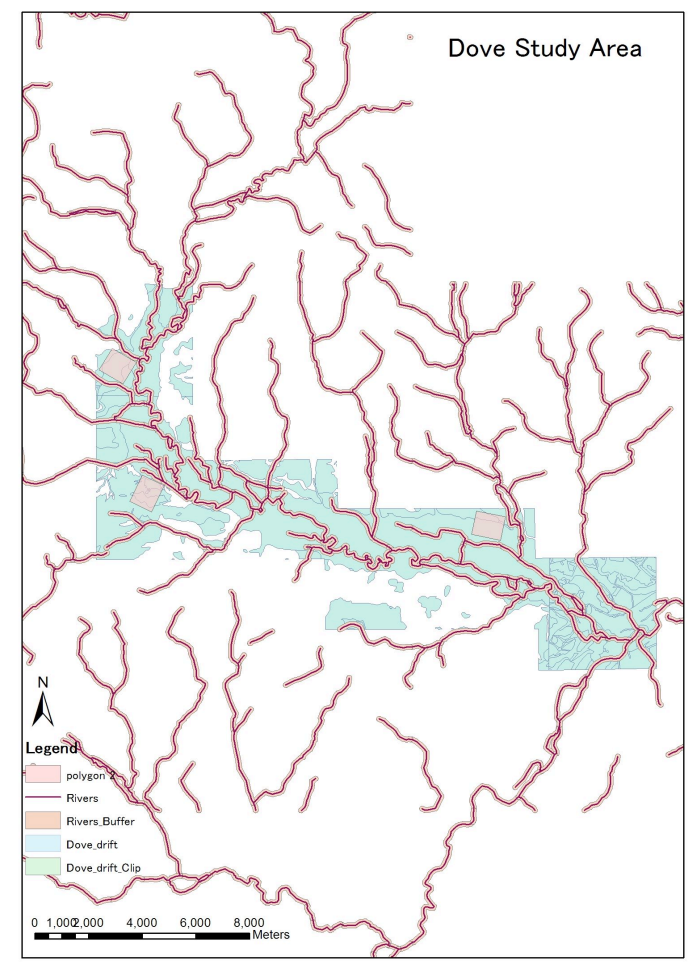

Figure 11: Locations of new quarry.

gons representing the three locations for the new quarry. Three polygons were created and placed in selected locations within the new shapefile. These polygons were opaque and the transparency display nature was adjusted (Fig. 11).

ArcGIS can work with many datasets at the same time. For this project the datasets were either shapefiles or tif photographs. ArcGIS assigns independent layers to all datasets. The layer order can be altered or adjusted. Each individual layer can be turned on or off. This allows the user to select the desired features necessary to achieve specific objectives. First one needs to arrange the layers in the desired order and to select which layers will be visible.

An important objective was to locate the quarry site in an area of sand and gravel or alluvium. The geology data was searched. Turning off all layers except the Rivers and the geology layers, the individual polygons were queried as to their geological qualities. Having noted the areas of sand and gravel and alluvium additional layers were switched on with the intent of searching for areas without restrictions. The Rivers buffer shapefile was turned on so as not to encroach within that zone.

Roads and built up areas needed to be established. The raster map images were selected next. Routes through and near areas of aggregate were identified and noted. The true nature of built up areas on the raster maps were sometimes obvious and sometimes ambiguous. To alleviate ambiguity aerial photographs were used to give clearer definition to the maps. This assisted in making decisions regarding the final locations. Once the nature of ambiguous ground features had been determined the aerial photographs were turned off and the previous map features again became visible.

Determining whether the sites came in contact with SSSIs, AONBs, SAMs or areas of Ancient Woodland was also a requirement. These four datasets were turned on to assess whether these areas appeared to come into conflict with the specified features. After viewing the data in the proper context it was determined that no conflict existed.

As these datasets were introduced into the GIS and viewed as a group indications of areas which could be appropriate for development became more apparent. To demarcate the three sites polygons representing the equivalent of 100 hectares needed to be created. In this case, rectangle polygons were created on a new polygon shapefile using the Editor function. 100 hectares is the equivalent of 1 square kilometer. The easiest way to project this is to use a square 1000 meters long by 1000 meters wide. An absolute square, though, proved to be problematic. By altering the dimensions, it soon became evident that using a rectangle shape to represent 100 hectares was a much more practical approach.

An adjustment to the mathematical equation is needed when using a rectangle. $1000 \mathrm{~m}$ X $1000 \mathrm{~m}$ equals $1,000,000$ square meters or 1 square kilometer. Multiplying $1200 \mathrm{~m} \mathrm{X}$ $800 \mathrm{~m}$, though, is less than 1 square kilometer. A different mathematical formula was needed. By using 1,000,000 as a basis and dividing it by the desired length, in this example, 1200, one can derive the appropriate width, 833.3. This formula can be used with any desired length or width to derive the other dimension.

A search of all areas that fit the list of requirements was undertaken. Rectangles of varying dimensions, representing 100 hectares, were used in the search. If rectangle dimensions appeared to be inappropriate they were removed and new rectangles with different dimensions were created. By using this methodology three areas which met the search criteria were designated.

\section{Results}

Three sites were located and designated as having the potential to support aggregate extraction without having serious implications for the environment and existing human constructions. These sites are located within the Dove River Valley and will be described from the upper left to the right as seen on the map. The first site (Site 1) is in the northwest, north of Uttoxeter and west of the Dove River. The second site (Site 2) is in the western portion of the valley, south of Uttoxeter and west of Marchington, southwest of the river. The third site (Site 3) is located in the eastern part of the valley, between Hatton and Hilton, north of Marston on Dove and north of the river (Fig. 12).

Site 1 is 100 hectares in size with dimensions of 1050 meters by 952.38 meters. The northwest and southwest corners of the site are in areas of unsorted glacial sediment. The northeast is alluvium. The remainder is sand and gravel. Most of the site is appropriate for aggregate extraction. Site 1 has no conflicts with SSSIs, AONBs, SAMs or areas of Ancient Woodland (Fig. 13).

The site is west of the Dove River. Tributaries border it 


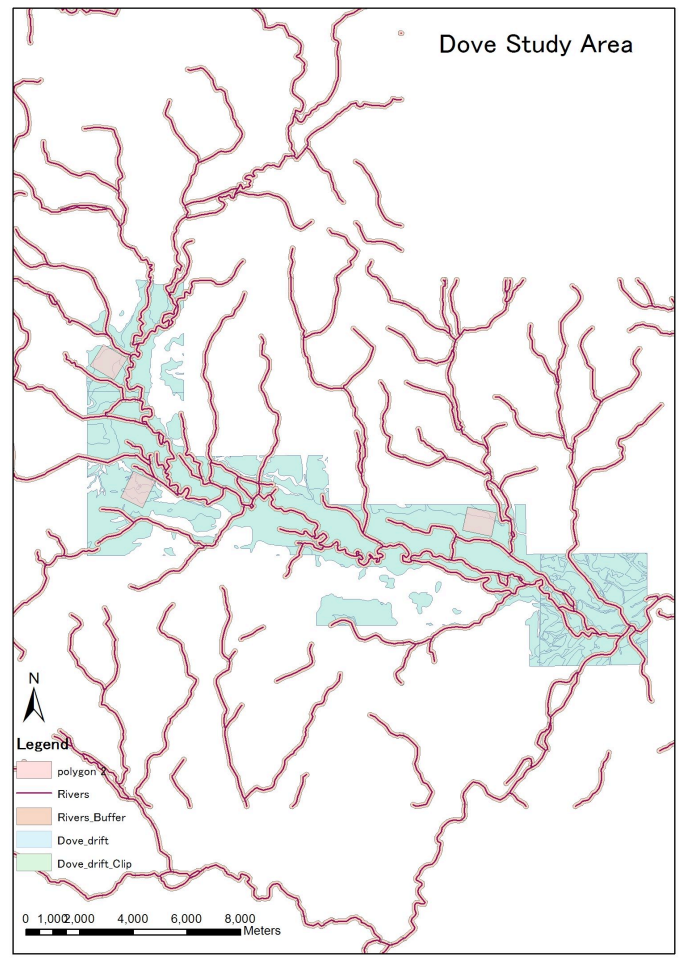

Figure 12: Three sites.

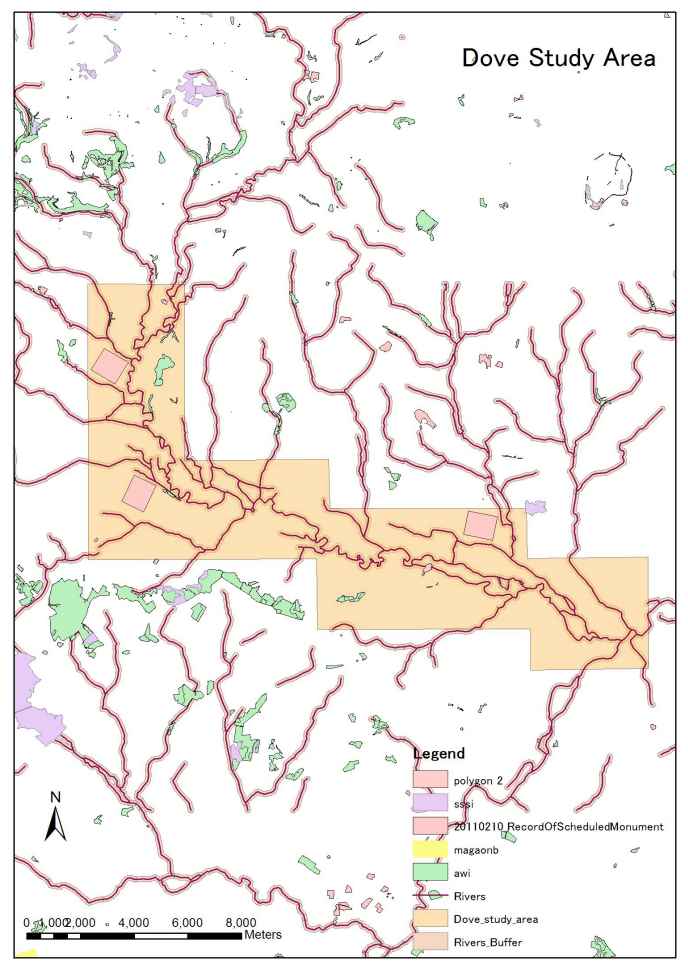

Figure 13: TBN.

on the north and south. The site does not encroach within 100 meters of any waterways. While there are no built up areas the site does occupy the Crakemarsh farm area. Road

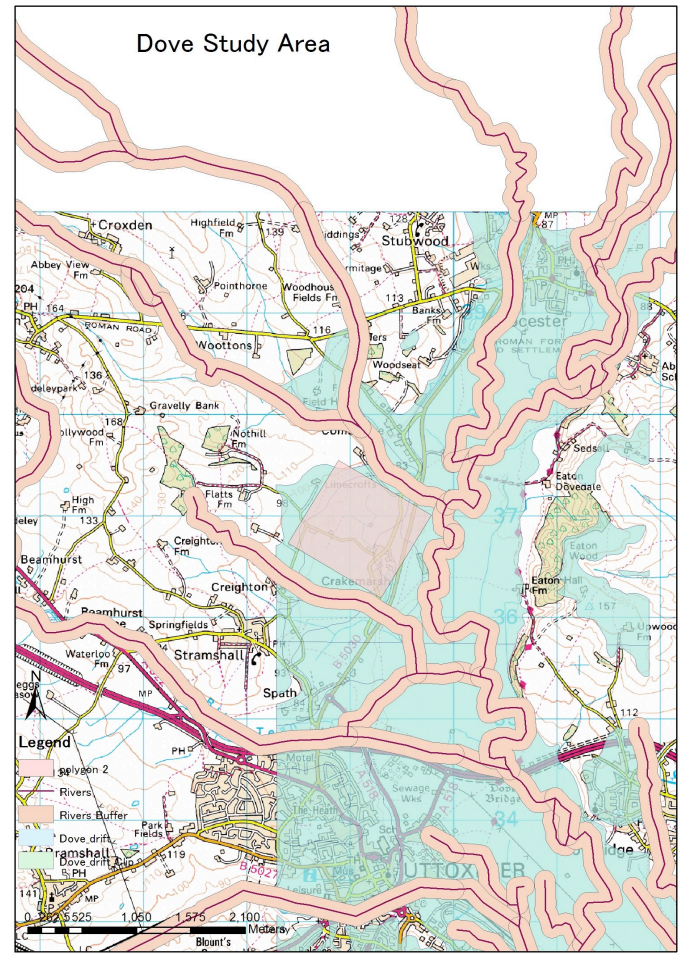

Figure 14: TBN.

B5030 passes directly through the eastern portion of the site, giving clear access to suitable infrastructure. Site 1 fulfills the stipulated planning criteria for granting a new quarry license. Most of the land within the extent of the site appears to be appropriate for aggregate extraction (Fig. 14).

Site 2 is 100 hectares with dimensions of 1100 meters by 909.09 meters. A portion in the northern third of the site is composed of sand and gravel. Another portion ranging from the center of the site to the south is also composed of sand and gravel. The remainder of the site is composed of till. It appears to be adequate for aggregate extraction. Site 2 has no conflicts with SSSIs, AONBs, SAMs or areas of Ancient Woodland (Fig. 13). The site lies southwest of the Dove River and lies directly below several tributaries. This site does not come within 100 meters of any waterways.

There are no truly built up areas near this site but there are a number of small farms and private houses located within the proposed site. Also there are what appear to be houses near the southeastern corner and Woodland Hall on the east side. Road B5017 traverses the southwest corner of the proposed site and provides direct access to suitable infrastructure. Site 2 does fulfill the stipulated planning criteria for granting a new quarry license. While apparently not as extensive as in Site 1 the extent of the sand and gravel in Site 2 would appear to provide financial incentive to proceed with aggregate extraction (Fig. 15).

Site 3 is also 100 hectares with dimensions of 1100 meters by 909.09 meters. Approximately the northern one forth is composed of sand and gravel. The remainder is composed of alluvium. The entirety of the site appears to 


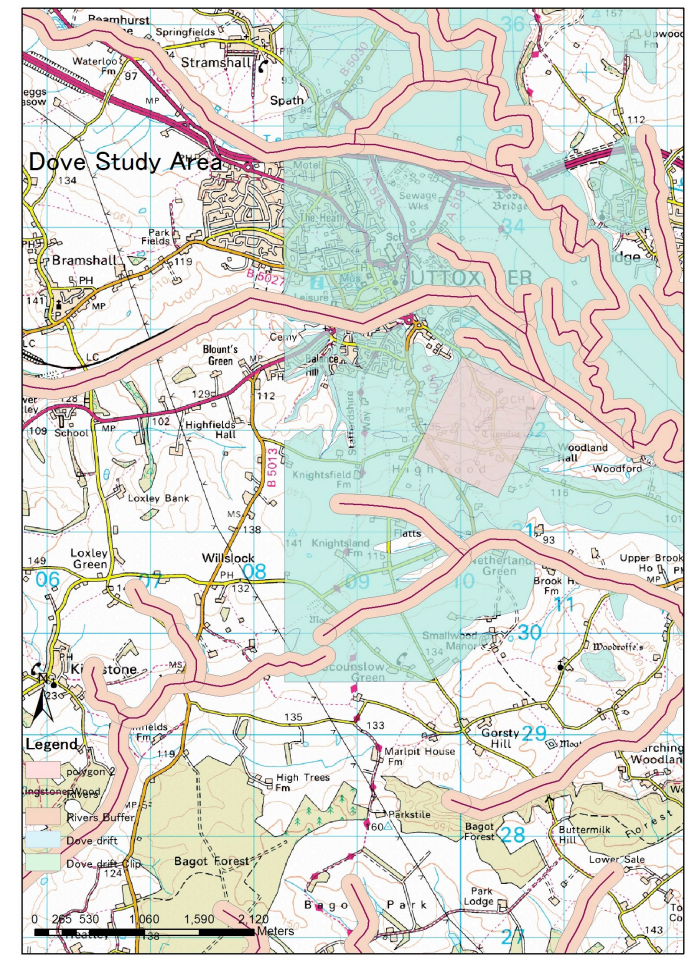

Figure 15: TBN.

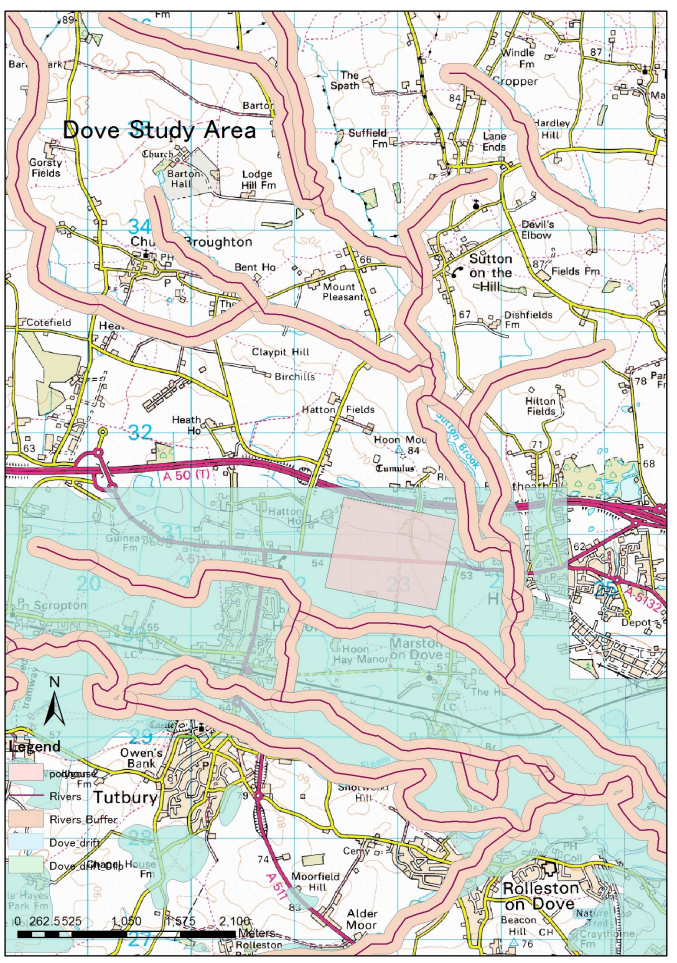

Figure 16: TBN.

be capable of being developed for aggregate extraction. As with Site 1 and Site 2, Site 3 is free of conflict with SSSIs, AONBs, SAMs or areas of Ancient Woodland (Fig. 13).
The site lies north of the Dove River with tributaries to the east and the south. Site 3 is some distance from these tributaries and does not come into contact with the 100 meter buffer zone around the waterways. There are no built up areas near or within the dimensions of the proposed site. Two houses appear to lie near the northwest corner but not within the extent of the proposed site. Road A511 passes from east to west through the middle of the proposed site allowing for direct access to suitable infrastructure.

Site 3 fulfills the stipulated criteria for granting a new quarry license. The presence of both, sand and gravel, as well as alluvium over the full extent of the proposed site offer financial incentive for aggregate extraction (Fig. 16).

\section{Conclusions}

Firstly, clearly defined criteria are essential. Some questions come to mind. It was stated that either sand and gravel or alluvium are to be quarried. Are sand and gravel more highly valued than alluvium or of equal value? Does this present a determining factor in site selection? Does a road of class B or higher refer to A roads (expressways) with controlled/limited access passing through sites without available access points? Would a highly developed road which is not a class B road be sufficient? Does watercourse mean any body of water or does this refer only to the available rivers dataset? Does a built up area describe urban and industrial sites or are there other implications? If all of these points were clearly defined the decision making process would be less confusing.

These ambiguities are reflected in decisions which were made. Potential areas were excluded because of uncertainty regarding criteria. Issues regarding criteria affected selected sites also. North of Sudbury and to the east there are potential areas. They were rejected because of uncertainty regarding road issues and the meaning of built up areas.

Site 1 was selected although some questions remained regarding watercourses. It was placed close to three watercourses. It does not breach the 100 meter buffer zone but within the site there are, on the raster map, what appear to be smaller waterways. This requires further clarification. Site 2 is problematic. There are several houses and farms within the site. It is unclear whether this is a built up area.

Representing the sites as rectangles should also be addressed. Sometimes representation with polygon shapes may be a more efficient and economically feasible consideration. Separating sites into multiple non-contiguous areas should be considered. For this, a thorough understanding of the land purchase proposal is necessary. Knowledge of appropriate zoning and tax laws would also be useful.

Decision making for this project was influenced by multiple factors, both straight-forward and ambiguous. Three areas which have fulfilled the requirements for a site have been put forward. As the approaches to satisfying the criteria requirements were not identical in all cases it may prove beneficial to show an order of preference regarding the final selection of the new quarry site.

Site 2 appears to be the most problematic. While fulfilling the criteria requirements, potential for residential dis- 
placement and financial compensation needs to be resolved. Lacking borehole data to assess aggregate depth, the underwhelming amount of sand and gravel would require evaluation to determine profitability. Although valid, this site probably offers the least amount of financial return and the largest amount of societal disruption.

Site 1 appears to have more potential than Site 2. It does have the burden of being bordered on three sides by designated watercourses. In times of extreme flooding this may prove problematic. Additionally, when examining the raster maps, there appear to be small watercourses which are not recognized on the Rivers shapefile. The nature of these watercourses is undetermined. The Crakemarsh farm area may require compensation. Site 1 does appear to have more potential than Site 2.

Overall, Site 3 shows the most potential for a less invasive and more profitable form of aggregate extraction. The entire extent of the site is located in areas of either sand and gravel or alluvium. An adequate road traverses the full extent from east to west. Residential displacement appears negligible or non-existent thus reducing the risk of compensation. If one site needs to be selected based on the existing criteria requirements, then Site 3 clearly offers the most potential for successful development.

\section{References}

[1] D. Wheatley and M. Gillings, "Spatial Technology and Archaeology", the Archaeological Applications of GIS. London, UK: Taylor and Francis, 2002.

[2] J. Conolly and M. Lake, "Geographical Information Systems in Archaeology - Manuals in Archaeology". Cambridge, UK: Cambridge, 2006

[3] J. C. Thill, "Geographic Information Systems for Transportation in Perspective, Transportation Research Part C: Emerging Technologies", UK: Elsevier, Vol.8, Issue 1-6, pp.3-12. London, 2000.

[4] H. J. Miler, "Potential Contributions of Spatial Analysis to Geographic Information Systems for Transportation (GIST)", Geographical Analysis, USA: The Ohio State University, Vol.31, Issue 4, pp.373-399, 1999.

[5] J. H. Ratcliffe and M. J. McCullagh, "Chasing Ghosts? Police Perception of High Crime Areas", British Journal of Criminology, UK: Oxford, Vol.41, Issue 2, pp.330-341. London, 2001.

[6] D. Z. Sui and R. C. Maggio, "Integrating GIS with Hydrological Modeling: Practices, Problems and Prospects, Computers, Environment and Urban Systems", UK: Elsevier, Vol.23, Issue 1, pp.33-51, London, 1999.

[7] G. H. Huang and J. Xia, "Barriers to Sustainable WaterQuality Management", Journal of Environmental Management, USA: Guilford, Vol.61, Issue 1, pp.1-23. London, 2001.

[8] J. Krygier and D. Wood, "Making Maps", Second Edition: A Visual Guide to Map Design for GIS, New York, 2001.
[9] A. P. Clevenger, J. Wierzchowski, B. Chruszcz and K. Gunson, GIS-Generated, "Expert-Based Models for Identifying Wildlife Habitat Linkages and Planning Mitigation Passages", Conservation Biology, Vol.16, Issue 2, pp.503-514, 2002 .

[10] Q. Weng, "Land Use Change Analysis in the Zhujiang Delta of China Using Satellite Remote Sensing, GIS and Stochastic Modelling", Journal of Environmental Management, UK: Elsevier., Vol.64, Issue 3, pp.273-284, London, 2002.

[11] L. R. Iverson, M. E. Dale, C. T. Scott and A. Prasad, "A GISderived Integrated Moisture Index to Predict Forest Composition and Productivity of Ohio Forests (U.S.A.)", Landscape Ecology, Netherland: Kluwer, Vol.12, pp.331-348. Amsterdam, 1997.

[12] E. Chuvieco and J. Salas, "Mapping the Spatial Distribution of Forest Fire Danger Using GIS", International Journal of Geographical Information Systems, Vol.10, No.3, pp.333-345, 1994. Taylors \& Francis Online, DOI:10.1080/02693799608902082, available on July $11,2013$.

[13] L. Yorke, "Advancing the Agenda in Archaeology and Alluvium". University of Newcastle, England. 2002.

[14] M. White, D. Bridgland, and A. Howard, "The Lower and Middle Palaeolithic Occupation of the Middle Trent and Lower Trent Catchment and Adjacent Areas, English Heritage. Project Design 3495PD, For Funding from the Aggregate Levy Sustainability Fund Administered by English Heritage". English Heritage, England.2005.

[15] D. Knight, "Making Archaeology Matter". York Archaeological Trust. York, England, 2006.

[16] K. Challis, "Experimental Mapping of the Risk Management of Encountering Buried Archaeology in Aggregate Landscapes, Project Number 5700". Birmingham Archaeology, University of Birmingham, p. 9. England, 2009.

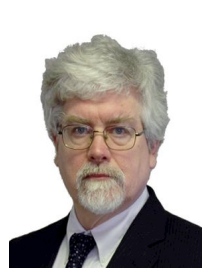

Dale Steele (Member) received BA, MA, and MFA degrees from the University of Wisconsin Madison in the USA. He is currently an Associate Professor at the University of East Asia in Shimonoseki, Japan. He is also a lecturer at Kyushu Sangyo University and Nishinippon Institute of Technology. He has been applying himself to the field of Landscape Archaeology for the past several years.

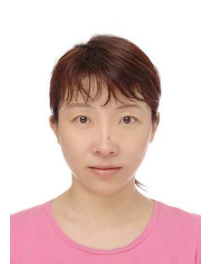

R.Zhang (Member) received the B.EC. degree from Dongbei University of Finance and Economics, China and the M.Ed. degree from Fukuoka University of Education, Japan. Since April 2005, she has been an associate professor at Nishinippon Institute of technology, Japan. Her research interests include educational engineering, English language teaching and intercultural communication study. 